\title{
Steve Murphy, Jean-Pierre Cauvin, Jean Jaques Lefrère, La gemnèse sous le manteau: Les Stupra de Rimbaud e Verlaine
}

\section{Isabella Giovinazzo}

\section{(2) OpenEdition \\ Journals}

Edizione digitale

URL: https://journals.openedition.org/studifrancesi/38062

DOI: $10.4000 /$ studifrancesi.38062

ISSN: 2421-5856

\section{Editore}

Rosenberg \& Sellier

\section{Edizione cartacea}

Data di pubblicazione: 15 décembre 2004

Paginazione: 637

ISSN: 0039-2944

\section{Notizia bibliografica digitale}

Isabella Giovinazzo, «Steve Murphy, Jean-Pierre Cauvin, Jean Jaques Lefrère, La gemnèse sous le manteau: Les Stupra de Rimbaud e Verlaine», Studi Francesi [Online], 144 (XLVIII | III) | 2004, online dal 30 novembre 2015, consultato il 08 mai 2021. URL: http://journals.openedition.org/studifrancesi/38062 ; DOI: https://doi.org/10.4000/studifrancesi.38062

Questo documento è stato generato automaticamente il 8 mai 2021.

\section{cc) (†) $\odot$}

Studi Francesi è distribuita con Licenza Creative Commons Attribuzione - Non commerciale - Non opere derivate 4.0 Internazionale. 


\title{
Steve Murphy, Jean-Pierre Cauvin, Jean Jaques Lefrère, La gemnèse sous le manteau: Les Stupra de Rimbaude Verlaine
}

\author{
Isabella Giovinazzo
}

\section{NOTIZIA}

STEVE MURPHY, JEAN-PIERRE CAUVIN, JEAN JAQUES LEFRÈRE, La gemnèse sous le manteau: Les Stupra de Rimbaud e Verlaine, «Histoires Littéraires», 2003 no. 14, pp. 35-46

1 L'articolo presenta il trittico di sonetti scritti a quattro mani dai due poeti nel corso della loro vita comune, e pubblicati per la prima volta nel 1923 da Albert Messein senza i nomi degli autori, sia per l'argomento osceno che per la non sicura attribuzione delle parti della composizione, anche se già apparsi «sous le manteau» in altre pubblicazioni La riproduzione presentata dalla rivista è tratta da un documento custodito presso l'università di Austin: si tratta della trascrizione di una lettera di Verlaine a Vittorio Pica del 1895, nella quale il poeta ricostruisce i testi con alcune incertezze nella memoria, come dimostrano le varianti rispetto alle altre versioni esistenti sia precedenti che successive, anch'esse trascrizioni celate all'interno di altri testi, la cui storia è brevemente riferita nelle pagine dell'articolo precedenti la riproduzione fotografica. 